\title{
Pneumolysis: a fundamental concept in COVID-19 lung disease
}

Gustavo R. Zubieta-Calleja ${ }^{1}$, Natalia Zubieta-DeUrioste ${ }^{1}$, Felipe de Jesús Montelongo ${ }^{2}$, Manuel Gabriel Romo Sanchez ${ }^{2} \&$ Murray Epstein ${ }^{3}$

1. High Altitude Pulmonary and Pathology Institute (IPPA), La Paz, Bolivia.

2. Hospital General de Ecatepec "Las Américas", ISEM, México

3. University of Miami Miller School of Medicine, Miami, USA

Keywords: HAPE, SARS-CoV-2, ACE-2, EPO, Lung sequelae, Kawasaki disease COVID-19 tongue

Running title: Pneumolysis in COVID-19 lung disease

\section{Corresponding author:}

Prof. Dr. Gustavo R. Zubieta-Calleja

Director

High Altitude Pulmonary and Pathology Institute (HAPPI-IPPA)

www.Altitudeclinic.com

Av. Copacabana - Prolongación \# 55, Teleféricos Celeste y Blanco,

Estación Av. Del Poeta, La Paz, Bolivia.

E-mail: gzubietajr@gmail.com;Cel: 591-73258026.

Prof. Dr. Gustavo Zubieta-Calleja ORCID: 0000-0002-4283-6514

Dr. Natalia Zubieta-DeUrioste ORCID: 0000-0003-2675-5025

Declaration of interest: None.

Funding: This research did not receive any specific grant from funding agencies in the public, commercial, or notfor-profit sectors. 


\section{ABSTRACT}

\section{Background}

COVID-19 severe lung compromise often evolves to life-threatening hypoxia. The experience led to the implementation of standardized protocols assuming similarity to SARS-CoV. Impulsive use of ventilators ended in up to $88 \%$ fatality.

\section{Methods}

COVID-19 pathophysiology and histopathological lung biopsy photomicrographs are analyzed.

\section{Results}

Pneumolysis is defined as progressive alveolar-capillary destruction resulting from the CoV-2 attack on pneumocytes. The histopathological results show the presence of Masson bodies, alveolar coating cells with nuclear atypia, reactive pneumocytes, reparative fibrosis, intraalveolar hemorrhage, moderate inflammatory infiltrates, microabscesses, microthrombus, hyaline membrane remnants, and emphysema. The three theoretical pathophysiological stages of progressive hypoxemia (silent hypoxemia, gasping, and death zone) are depicted.

\section{Conclusion}

Silent hypoxemia suddenly evolves to critical hypoxemia. This, as a consequence of progressive pneumolysis + inflammation + overexpressed immunity + autoimmunity + HAPE-type edema resulting in acute pulmonary insufficiency. The proposed treatment (based on Tolerance to Hypoxia and the Hemoglobin factor) includes: prompt oxygen administration, inflammation and immunity reaction control, antibiotics, rehydration \& anticoagulation. 


\section{Introduction}

Coronavirus disease 2019 (COVID-19), produced by the infection with Coronavirus (CoV-2), surprised the world with the first cases in Wuhan, China. It continues to grow and has been referred to as the most significant public health crisis since World War II (Mitra et al., 2020). The patients presented flue-type variable symptomatology with headaches, muscle pain, weakness, diarrhea, dry cough that could suddenly evolve to critical hypoxemia and subsequent death (Lin et al., 2020). The first lung CAT scans were quite alarming as it was evident that multiple areas of the lungs presented a severe compromise. It was immediately referred to as SARS-CoV-2 pneumonia, assuming that it was the same pathology as SARS-CoV-1 (Adhikari et al., 2020). Severe cases with a $\mathrm{SpO}_{2}<90 \%$, at sea level, were placed on ventilators. Unfortunately, and quite surprisingly, between $50 \%$ and $88.7 \%$ of those intubated and on ventilators died, although this last percentage was modified, showing only a $3.3 \%$ survival, $24.5 \%$ death, and $72.2 \%$ remaining hospitalized (Richardson et al., 2020). Understandably, this was quite alarming and showed that this disease was very aggressive in about $5 \%$ of those infected with irreversible lung damage, classified as pneumonia (Sohrabi et al., 2020). As of December 6th, 2020, there were 66.7 Million infected people worldwide with 1.53 Million deaths, with 205,513 new cases in the US with a total death toll of 281,202 in a steep rise (NYTimes, 2020). Pneumonia in COVID-19 has been previously questioned (Pomara et al., 2020).

The term pneumolysis or, more commonly, pneumonolysis originated in the early 20th century. The term was used in thoracic surgery to liberate fibrotic tissue adhering to the parietal pleura from the lung pleura, inducing lung collapse in pulmonary Tuberculosis. A more common term used for this was plombage (also known as decortication). Plombage fell into disfavor in the 1940s due to the development of Tuberculosis treating medication (Braimbridge, 1993; Daniel, 2006). In an attempt to avoid confusion, an alternative terminology to Pneumolysis in COVID-19 could be Pulmolysis or Pulmonolysis based on the Latin word Pulmo = lung. Perhaps this will end up being the right terminology, but for the moment, we suggest continuing with pneumolysis based on Greek semantics. 
The concept of pneumolysis acquires transcendental importance to understand this highly aggressive viral pathology that is changing our world in everyday life, economy, and global health. Our view on how COVID-19 lung damage occurs and our pathological findings can help improve this devastating pathology's fatal outcomes.

\section{Pneumonia}

Pneumonia or Pneumonitis is classically defined as an acute disease marked by inflammation of lung tissue accompanied by infiltration of alveoli and often bronchioles with white blood cells (such as neutrophils) and fibrinous exudate, characterized by fever, chills, cough, difficulty in breathing, fatigue, chest pain, and reduced lung expansion, and typically caused by an infectious agent (such as a bacterium, virus, or fungus) (Merriam-Webster Dictionary). Notice that the suffix "itis" denotes inflammation.

Pneumonia's first known use dates back to Hippocrates (460-370 BC) (Feigin, 2004), coming from the Greek word $\pi v \varepsilon u ́ \mu \omega v$ (pneúmōn), meaning "lung"(Stevenson, 2010).

It becomes evident that, at the time, the term pneumonia was solely based on clinical and/or pathological findings. The classical symptomatology included intense chest pain (as if being stabbed), bloody sputum, and shortness of breath (Periselneris et al., 2020). From the pathologists' point of view, there were four stages: Consolidation, Red hepatization with red blood cells, neutrophils, and fibrin present in the pulmonary alveolus/ alveoli; followed by Gray hepatization, where the red cells had been broken down, leaving a fibrinosuppurative exudate and finally Resolution (Pahal and Sharma, 2020).

There was no radiology at the time, as it was invented by Roentgen in 1895, from when it became an important diagnostic tool (Felson et al., 1949), even to visualize ventilator-associated pneumonia (Wunderink et al., 1992). Pneumonia was defined as being of three types:

Bronchopneumonia (Staphylococcus aureus), Lobar or alveolar pneumonia (Streptococcus), and Interstitial pneumonia (Viral or Mycoplasma). Currently, in autopsy studies, the classification includes Community-Acquired Pneumonia (CAP) or Hospital-acquired Pneumonia (HAP) (Blasi et al., 2007). The WHO's annual incidence of pneumonia was last estimated in 2008, as 450 million cases and 4 million deaths (Bartolf and Cosgrove, 2016). 
In 2019, the COVID-19 CAT Scan lung compromise presented a different pathology (Fig. 1). Some authors noted that it was something different but did not quite understand it and suggested autopsies be performed (Pomara et al., 2020). Several autopsy studies of COVID-19 show a fibrotic, bullae filled, necrotic lung tissue, clearly distinctive from the SARS-CoV-1 that is more hemorrhagic (personal communication by Paolo Pelosi). Others reported diffuse alveolar damage (DAD), chronic lung inflammation, and edema in the bronchial mucosa, some finding thromboembolic events (Barton et al., 2020; Edler et al., 2020; Wichmann et al., 2020).

\section{Pneumolysis}

COVID-19, an overly aggressive disease new to human kind, made us question whether it was indeed a type of pneumonia. For this reason, the first author coined a new terminology to describe the disease more accurately, explain the pathophysiology of silent hypoxemia present in COVID-19, and hence improve the focus of treatment (Zubieta-Calleja and Zubieta-DeUrioste, 2020; Zubieta-Calleja et al., 2020). The term "Pneumolysis" based on Greek etymology pneumo=lung and lysis=destruction, was first used and proposed during the International Conference on Coronavirus Viral Genomics in India on-line on June 7th - 10th, 2020, commented to Dr. Paolo Pelosi, an Italian intensivist and world-renown mechanical ventilation expert (Zubieta-Calleja, 2020). The term "lysis" in the Merriam-Webster dictionary is defined as "a process of disintegration or dissolution (as of cells)".

\subsection{Definition}

Consequently, we propose the following definition:

Pneumolysis is an acute infectious disease marked by inoculation of the Coronavirus-2 RNA or other viruses within the pneumocytes, viral intra-cellular replication and pneumocyte destruction (generally not compromising the bronchioles), accompanied by inflammation, edema, capillary vasodilatation, the formation of hyaline membranes, and micro-abscesses, nuclear atypia, characterized by non-productive cough, initial silent hypoxemia, and sudden onset of difficulty in breathing, fatigue, tachycardia and rapid progression to a reduced lung gas exchange area and subsequent fibrosis. First known use: Jun 13, 2020. 


\subsection{Incidence}

The CoV-2 pandemic is asymptomatic for $75 \%$ of the population and symptomatic for $25 \%$, which can suffer a multiple disease variant with about 2-3\% Case Fatality Rates, mostly due to severe pulmonary compromise (Madabhavi et al., 2020).

\subsection{Symptomatology}

The patients that suffer lung compromise in the CoV-2 pandemic can present silent hypoxemia with $\mathrm{SpO}_{2}<95 \%$ at sea level $\left(\mathrm{SpO}_{2}<85 \%\right.$ at 3,600m), accompanied by shortness of breath upon mild exercise, fever, tachycardia, tachypnea, hyperventilation, with intercostal, muscular and diaphragmatic fatigue, the sensation of drowning, gasping and subsequent death.

Other symptomatology in other organs can likewise be present as we have affirmed that CoV-2 produces not only pneumolysis (Zubieta-Calleja et al., 2020) but multiple diseases in other organs and even endothelitis causing endothelial damage (Ackermann et al., 2020), and possibly the formation of thrombus, generated in the ACE-2 receptor Coronavirus binding (Teuwen et al., 2020).

\subsection{Diagnosis}

Diagnosis is based on the presence of a pandemic, $\mathrm{SpO}_{2}<90 \%,\left(\mathrm{PaO}_{2}<60 \mathrm{mmHg}\right)$ at sea level, and lower as altitude increases, CAT scan with typical multiple area compromise, ground-glass images, crazy ground paving, and consolidation areas (Pan et al., 2020), a positive reversetranscription polymerase chain reaction (RT-PCR) tests PCR and possibly Elisa with the presence of $\mathrm{M}$ and $\mathrm{G}$ antibodies. With the latter false negatives have been reported, so they should be interpreted cautiously (Xie et al., 2020). Chest CT has the highest sensitivity for COVID-19 diagnosis (Ai et al., 2020).

\subsection{Differential Diagnosis}

This "new" pathology differentiates itself from High Altitude Pulmonary Edema (HAPE), which occurs on a rapid ascent to high altitude in some individuals (Fig. 2). HAPE patients can walk-in to consultation with a $\mathrm{PaO}_{2}$ as low as $30 \mathrm{mmHg}$ in the city of $\mathrm{La} \mathrm{Paz}(3,500 \mathrm{~m})$ (Fig. 3). The adequate treatment gives rise to full resolution and lung edema reabsorption, typically in 2 days 
in children and sometimes lasting up to several days in adults (Zubieta-Calleja and ZubietaCastillo, 1989). Whereas in pneumolysis, there is lung pneumocyte destruction followed by inflammation, HAPE-type edema, and some minor hemorrhage, giving rise to severe lung damage diagrammatically depicted in Fig. 4. HAPE-type edema could be present since the pneumolysis reduces the gas exchange surface significantly. Consequently, the patient is placed at incrementing altitude, some even reaching $\mathrm{PaO}_{2}$ values similar to those found on the summit of Mt. Everest (Zubieta-Calleja and Zubieta-DeUrioste, 2020; Zubieta-Calleja et al., 2020). The normal remaining lung tissue can suffer edema as it results from extreme hypoxia, pulmonary hypertension, and stress failure of capillaries (Zubieta-Calleja and Zubieta-Castillo, 1989).

SARS-CoV pneumonia is a different pathology where there is a "Grey hepatization" type lung compromise (presented in Paolo Pelosi's conferences), with a much heavier weight found in autopsies as it is severe fluid retention due to edema.

Differentiation with H1N1 influenza presented in 2009 is likewise essential (Tang et al., 2020). COVID19 had a significantly less productive cough than that of patients with H1N1. Fatigue, GI symptoms, and myalgia in patients with COVID-19 were more significant than those with H1N1. Transaminase, lactate dehydrogenase, and troponin I levels were significantly lower in patients with COVID-19. In terms of imaging characteristics, ground-glass opacity on chest CT scans was more common in patients with COVID-19 (Tang et al., 2020).

\section{Similarities and differences between COVID-19 and Tuberculosis (TB)}

COVID-19 is a fast-track production of emphysema-type lesions as it produces destruction of alveoli without time for remodeling and adaptation. It creates bullae (Fig. 1) and a form of small cavities similar to what happens in TB. These bullae were also present in previous biopsies (Robba et al., 2020). The mycobacterium tuberculosis proliferates inside alveolar macrophages and eventually kills the cells (Serafino Wani, 2013). The tuberculosis attack is intracellular, making the treatment difficult and requiring long-term therapy for up to a year. The infected macrophages produce cytokines and chemokines that attract other phagocytic cells, including monocytes, other alveolar macrophages, and neutrophils, which eventually form a nodular granulomatous structure called the tubercle (Pai et al., 2016). However, this takes quite a bit of time. In COVID-19, there is no time, as the intra-cellular coronavirus bio-attack is fast. The same 
phagocytic cells are, however, present in COVID-19 as described below. Adaptation to survival within disease takes time. The high altitude adaptation formula shows a typical hematopoietic time frame in response to ascent to a fixed high altitude (Zubieta-Calleja et al., 2007) that requires 40 days for an optimal increase of the hematocrit at 3,600m $(12,000 \mathrm{ft}$.).

\section{COVID-19 Pathology}

The histopathological findings of 19 patients who died from severe pneumolysis resulting from SARS-CoV-2, and adult respiratory distress syndrome, in the intensive care unit of the General Hospital of Ecatepec, of the Health Institute of the State of Mexico, Mexico, are presented as preliminary findings (Fig. 5). Death time from starting mechanical ventilation was, on average, 16 days. Ultrasound-guided biopsies of the lungs immediately post-mortem were performed. The most important manifestation at the time of death of these patients, in addition to refractory hypoxemia, was the retention of $\mathrm{CO}_{2}$ (hypercapnia) with an average of $90 \mathrm{mmHg}$ (torr) in the arterial blood gases, which confirms the pathophysiology (Fig. 6 at sea level and Fig. 7 at high altitude). As shown by the following photomicrographs, the most important histopathological findings were the changes associated with diffuse alveolar damage (DAD). The latter is a general term used concerning ARDS (Petitjeans et al., 2016), but since we are now dealing with a new highly lethal pathology, new precise terminology is required. This is what we define as pneumolysis, an inflammatory process characterized by lung tissue derangement with alveolar collapse, hyaline tissue formation, some microhemorrhages, and micro-abscess possibly due to superinfection, with polymorphonuclear cells and monocytes infiltration. Furthermore there is, as well, a repair process with organizational changes of fibrinoid deposits, early fibroblastic interstitial fibrosis, and Masson's bodies. Additionally, the proliferation of fibroblasts and collagen with intense septal and para-septal reparative fibrosis can be observed, which significantly thickens the alveoli and explains the process of decreased gas exchange area and hypercapnia in pneumolysis. Other authors have found the virus only in the acute initial stage of lung compromise and not in the progressive late stage, where there was an immune response that possibly cleared the virus (Sauter et al., 2020). However, in our studies, the presence of reactive pneumocytes with nuclear atypia (nucleomegaly, hyperchromasia) is striking (Zubieta-Calleja and Zubieta-DeUrioste, 2020), indirectly indicative of active viral replication, even at the time of death. This is a very important observation, as it shows that the pneumocytes, due to the CoV-2 
aggression, with RNA inoculation within are changing the metabolite production code to replicate the virus. This means that either the emergency cellular condition gives rise to nuclear alterations or the virus itself does alter the nuclei, which needs to be further investigated. The replication process is carried out in the lysosomes, the endoplasmic reticulum, and the Golgi complex (Sureda et al., 2020). Likewise, there are heterogeneous areas of alveolar rupture. These changes were observed in $100 \%$ of patients. Other findings included: intra-alveolar hemorrhage in $54 \%$ of the patients, micro-abscesses by bacteria, fungi, and other opportunists such as pneumocystis in 50\% of the patients, a finding of great importance since it was thought that most of the patients had died from pneumonia associated with mechanical ventilation. Likewise, microthrombi were found in $37 \%$ of the patients, which is not consistent with previous studies. It should be noted that $100 \%$ of the patients had prophylactic anticoagulation at the time of death.

We can conclude that the patients presented an active process of cell destruction (pneumolysis) by active viral replication, with persistent infiltration of inflammatory cells, as well as a continuous repair process, but with a reactive fibrotic activity that was reparative but so intense that in the end led to death. Furthermore, these multiple findings, with superimposed opportunistic infections, complicated the evolution of the disease.

Pathologic studies using post-mortem transbronchial lung cryobiopsies showed the presence of "pneumocyte loss with discontinuation of the alveolar epithelial lining, hyaline membranes, intra-alveolar fibrinous exudate, early fibroblastic interstitial fibrosis, obliteration of the alveolar structure by fibrosis, type 2 pneumocyte hyperplasia and atypia, Mallory-like intracytoplasmic inclusions in type 2 pneumocytes, micro-honeycombing, foci of bronchopneumonia, vasculitis or vascular thrombosis" (Barisione et al., 2020). They also refer to the lesions as Diffuse Alveolar Damage (DAD) and 3 phases 1) early/exudative phase, 2) mid/proliferative phase, and 3) late/fibrous phase DAD with honeycombing. We believe honeycombing in this disease is the result of pneumolysis as in comparative fast-track emphysema.

A gel-like fluid has been found in autopsy lung samples, and the presence of hyaluronan has been reported (Hellman et al. 2020). This substance is a semiflexible polymer chain of high molecular weight. It would apparently be highly hydroscopic (able to absorb 1,000 times its molecular weight) and induce the formation of edema. However, Paolo Pelosi has found that the 
weight of lungs from COVID-19 autopsies was much less than those of ARDS-CoV-1. The latter macroscopically look like a purple hepatization suggesting pneumonia. In contrast, COVID-19 autopsy lungs show extensive fibrous tissue and many bullae in a brownish lung. They have shown three main phenotypes for respiratory management in the CT: 1) multiple, focal, possibly over-perfused ground-glass opacities; 2) inhomogeneously distributed atelectasis; and 3) a patchy, ARDS-like pattern (Robba et al., 2020).

\section{COVID-19 Pathophysiology}

COVID-19 patients tend to present a predominance of pneumolysis in the lower lobes of both lungs. The probable explanation could be associated to aerodynamics and lung elasticity that initially respond with lower lobes distention on inhalation due to diaphragmatic contraction and direct main bronchi orientation, driving the $\mathrm{CoV}-2$ directly to impact the lungs in that area. It has been established that angiotensin-converting enzyme 2 (ACE-2) is the cellular receptor for severe acute respiratory syndrome-coronavirus (SARS-CoV) and the new coronavirus (SARSCoV-2) (Yan et al., 2020). The CoV-2 enters type 2 pneumocytes (Mason, 2020), and since these cells are next to type 1 pneumocytes and are sustaining them, they are destroyed, and the whole alveolar structure is seriously compromised, as evidenced in several studies. The possible pathophysiological responses have been described in a paper entitled "Pneumolysis and Silent Hypoxemia" (Zubieta-Calleja and Zubieta-DeUrioste, 2020). Fig. 6 shows the pathophysiologic changes in COVID-19. Some newspaper interviews and publications in a local bulletin in La Paz, Bolivia, have informed the public about this new terminology and its implications (ZubietaCalleja, G \& Zubieta-DeUrioste, 2020).

Furthermore, as the pneumocytes are highly specialized cells that are elongated so as to reduce the width of the cell for an adequate oxygen and carbon dioxide diffusion distance, and as the CoV-2 are reproducing inside, they can impede the oxygen transfer by altering the diffusion.

However, as the disease progresses, all three hypoxia producing conditions are present (diffusion, ventilation/perfusion inequality, and above all shunts), and it is for this reason that supplementary oxygen is unable to raise the $\mathrm{SpO}_{2}$ to normal levels $(98 \%$ at sea level and $90 \%$ at 3,500m of altitude). Carbon dioxide (20 times more diffusible than oxygen) can still be adequately ventilated and expelled despite the significant reduction of the oxygen exchange 
surface (Fig. 6). It is essential to observe that the $\mathrm{SPO}_{2}$ falls linearly as the expansion of the pneumocyte invasion of the CoV-2 evolves. We initially thought it would be a curve; however, based on the actual blood gases data, it was concluded that it was most probably linear.

Displacement of the oxygen Saturation curve resulting from the Bohr effect is not so significant in our criteria, although it may aid in the delivery of oxygen to the tissues. However, since there is pneumolysis, the problem is the capture of oxygen in the lungs. However, an increased hematocrit as that present at high altitude becomes a great advantage and may explain the lower death rates observed at high altitude (Submitted Letter to the editor).

Originally, we also observed that there were not many $\mathrm{pH}$ or $\mathrm{PaCO}_{2}$ changes in the "Silent Hypoxemia" phase (Zubieta-Calleja and Zubieta-DeUrioste, 2020), with mild hyperventilation, as also described by (Tobin et al., 2020). The latter points out fundamental aspects; however, the whole picture is incomplete. In our experience, high altitude residents at 3,600m * as at any altitude) are, in reality, living with a permanent "silent hypoxemia". With this experience we are able to propose the explanation of the baffling "silent hypoxemia" in COVID-19. For this reason we postulated that during acute hypoxemia with the impossibility of raising the $\mathrm{PaO}_{2}$ and $\mathrm{SpO}_{2}$, a fundamental solution to save lives would be the use of extracorporeal oxygenation (ZubietaCalleja and Zubieta-DeUrioste, 2020) and the administration of erythropoietin (Soliz et al., 2020).

\subsection{Superimposed inflammatory reaction "cytokine storm"}

The inflammatory process in COVID-19 has been amply reported. It is referred to as the exuberant production of pro-inflammatory cytokines, significant cellular and humoral responses, generating extensive tissue injury in the "cytokine storm" (Bikdeli et al., 2020; Diamanti et al., 2020; Madabhavi et al., 2020; Pedersen and Ho, 2020). Furthermore, apoptosis of endothelial and epithelial cells and increased vascular permeability, and exaggerated $\mathrm{T}$ cell and macrophage responses attempt viral clearance (Channappanavar and Perlman, 2017). Mast cells release inflammatory mediators, including histamine, leukotrienes, and neutral proteases would also seem to be involved, generating lung injury (Theoharides et al., 2012). 


\section{2 "Reactive Autoimmune response"}

Once the CoV-2 enters the pneumocyte, and as it becomes an intra-cellular aggression factor, the organism tries to attack it, but as it cannot phagocyte as if it were a bacterium in the interstice (i.e. mycobacterum tuberculosis), the viral immune attack becomes imperiled. Furthermore, as the new CoV-2 with its capsule exits the cell, the immune system confuses structures, and an autoimmune reaction ensues (Dalakas, 2020; Galeotti and Bayry, 2020; Woodruff et al., 2020). This gives rise to many other pathologies such as arthritis, neuritis and myalgias. The actual lysis of the pneumocytes may come about as an auto-immune-type reaction (Galeotti and Bayry, 2020) due to the cytokine storm where the immune system tries to reach the CoV-2 within the cells, and in its attempt to destroy them, also destroys the pneumocyte. Furthermore, it has been said that the CoV-2 exits the pneumocyte, where it is being reproduced as exocytosis. i.e., the opposite of phagocytosis. As it is being expelled, carrying with it some cell wall, it would generate the autoimmune response that would later create the lysis of the pneumocytes. Some authors have found evidence of autoimmune disorders in COVID-19 (Diamanti et al., 2020; Woodruff et al., 2020). In autopsy studies, CD8+ T Cell-mediated cytotoxicity (autoimmunerelated) has been found in the lung and other organs (Ehrenfeld et al., 2020).

Kawasaki's disease, originally described in children, is a form of acute febrile systemic childhood vasculitis that has recently been found to be associated to COVID-19 (Ouldali et al., 2020; Toubiana et al., 2020). One of our patients at high altitude with a $\mathrm{SpO}_{2}$ of $70 \%$ presented coughing, and dyspnea. Her tongue had a peculiar color similar to that present in Kawasaki's Disease (Fig. 8). We concluded she had vasculitis and was started on Aspirin 500mg per day, along with oxygen, antibiotics, and analgesics. She evolved favorably.

This would explain why the corticosteroid therapy results very favorable as it would contribute also to reduce the autoimmune attack. This poses the possibility that pulsed immune-suppressing treatments could, at a certain stage, limit pneumolysis, a subject to be studied. 


\section{Pathophysiology at high altitude}

COVID-19 presented a "lagged" response of presentation in practically all high altitude cities of the world. Mortality has also been shown to be lower at high altitudes (Zubieta-Calleja et al. Letter to the editor: Patients with COVID-19 in high altitude areas of Bolivia and Peru have a substantially lower mortality rate. Accepted for publication HAMB). This can be explained by several factors. A higher hematocrit at a high altitude resulting from life in a chronic hypoxia environment can possibly be protective as oxygen administration can load much more oxygen with full hemoglobin saturation than at sea level with low hemoglobin (Zubieta-Calleja et al. 2020b). This "oxygen reserve pool" (ORP) in high altitude high blood hemoglobin is, in our criteria, a survival mechanism since the oxygen content is much higher than at sea level. The oxygen dissociation curve study comparing a normal high altitude resident (Ht of 43\%) and a patient with polyerythrocythemia $(\mathrm{Ht}=71 \%)$ shows this incremented ORP (see Fig. 4 in (Zubieta-Calleja, G.R., Ardaya, G., Zubieta, N., Paulev, 2013)). In COVID-19, the critically low hypoxia levels can be "buffered" if there is more hemoglobin. Erythropoietin is also elevated at high altitudes and plays a protective role in the lungs but also in endothelial cells, brain, heart, and other tissues (Ehrenreich et al. 2020; Soliz et al. 2020). Additionally, due to their constant exposure to chronic hypoxia, high altitude residents have a higher tolerance to hypoxia (ZubietaCalleja, G.R., Ardaya, G., Zubieta, N., Paulev 2013) and even extended longevity (ZubietaCalleja and Zubieta-DeUrioste 2017).

The pathophysiology of COVID-19 at high altitude is shown in Fig. 7, where the starting $\mathrm{PaO}_{2}$ is $60 \mathrm{mmHg}$ at $3,500 \mathrm{~m}$. The descent to critical hypoxia is not as steep as at sea level. This could help explain the lower incidence of death due to COVID-19 at high altitude.

\section{Pneumolysis Treatment}

The transcendental deduction is that intubation and high PEEP pressure in already friable and fragile lung tissue can give rise to adverse outcomes. It can produce alveolar rupture and the creation of bullae that is evident radiologically and in autopsy studies. Hence non-invasive high flow oxygen reducing respiratory dead-space and inducing a resting lung can be more effective in treating the acute phase provided lung destruction is not so extensively disseminated. 
The alterations produced by a gradual progression of the disease going from silent hypoxemia, gasping to death pathophysiologically result from the formation of intra-pulmonary shunts (due also to pneumocyte destruction), uneven ventilation/perfusion, and alterations of diffusion. All three pathological function alterations contribute to the progressively incrementing hypoxia. This seems to be why in severe COVID-19 cases, even up to $100 \%$ Fractional Inspired Oxygen Pressure $\left(\mathrm{FIO}_{2}\right)$ administered via nasal cannula or mask is insufficient in order to normalize a severely decreased $\mathrm{PaO}_{2}$. High flow nasal cannulas are a good alternative (Geng et al., 2020) if applied early with the objective to reduce the Baby Lung effect (Gattinoni et al., 2016) and the formation of what we describe as HAPE-type edema in normal lung tissue in COVID-19 (Zubieta-Calleja and Zubieta-DeUrioste, 2020). Treatment should include corticosteroids started as soon as the $\mathrm{SpO}_{2}$ drops and if typical COVID-19 lesions in the lung CAT-Scan are observed.

Diverse degrees of pulmonary fibrosis in a significant number of survivors and subsequent requirement of therapies habitually seen at sea level such as supplementary oxygen through concentrators will be of great importance. We and others have also suggested the use of erythropoietin in the treatment of severe pneumolysis cases (Ehrenreich et al., 2020; Soliz et al., 2020; Zubieta-Calleja et al., 2020) as it can help improve the oxygen transport to tissues of the compromised oxygen transport triad (pneumo-dynamic pump, hemo-dynamic pump, and hemoglobin) described before (Zubieta-Calleja et al., 2020). Several other authors are also suggesting the use of erythropoietin due not only to the increase of red blood cells, hematocrit and hemoglobin but also to the neuroprotective effects of the hormone itself in different tissues like the heart, the vessels, and the brain (Brenner, 2021; Ehrenreich et al., 2020; Fishbane and Hirsch, 2020; Hadadi et al., 2020; Leventhal et al., 2020; Miskowiak, 2020; Sahebnasagh et al., 2020).Furthermore, the increase of hemoglobin becomes a fundamental factor of hypoxia tolerance as previously described in the Formula of Tolerance to hypoxia $=\mathrm{Hb} / \mathrm{PaCO}_{2} * 3.01$. This formula states that higher hemoglobin and a lower $\mathrm{PaCO}_{2}$ give greater tolerance to hypoxia (Zubieta-Calleja, G.R., Ardaya, G., Zubieta, N., Paulev, 2013). The first two authors have used human recombinant erythropoietin 4,000 IU to treat several COVID-19 patients at high altitude recovering favorably with no complications. 
The use of mechanical ventilators in the treatment of COVID-19 can be quite detrimental. Since it is not a volume or pressure ventilation issue, it would be wiser to use a heart-lung machine instead until the autoimmune process is controlled and the inflammation is reduced.

Finally, it is suggested that the term Severe Acute Respiratory Syndrome (SARS) be dropped in COVID-19 as it is a different pathology present in SARS-CoV infections. A more adequate and differentiating term could be Severe Acute Pneumolysis Syndrome (SAPS-CoV-2).

\section{Post-COVID-19 sequelae}

Pneumolysis also explains the resulting pulmonary fibrosis in patients that survive, leaving them with a permanent respiratory insufficiency that will end up in poly-erythrocythemia as a compensatory factor (Zubieta-Castillo et al., 2006). This deduction is based on the experience of previously termed chronic mountain sickness and wrongly defined by others as "loss of adaptation". Quite the contrary, we define it as an adaptation of patients with respiratory and/or cardiac disease in a chronic hypoxic environment. The extent of recovery depends on the degree of Pneumolysis and fibrotic tissue. The further the extension of fibrosis, the lower the resting $\mathrm{PaO}_{2}$ and $\mathrm{SpO}_{2}$ can significantly reduce during exercise, thereby becoming a limiting factor. Recovery based on respiratory physiotherapy is being advised. However, when there is pneumolysis, the possibility of improvement seems limited. There is a possibility that stem cells in alveolar tissues may be able to regenerate the formation of alveoli (Schilders et al., 2016), which could explain some adequate recovery of people who suffered pneumolysis. This needs to be further studied. It is also highly possible that emphysema and barrel chest shapes may develop (the latter in an attempt to compensate for respiratory insufficiency). Pulmonary hypertension may also result in an effort to increase lung perfusion.

\section{Conclusions}

The description of Pneumolysis is fundamental for the understanding of the pulmonary affectation in COVID-19. It helps explain progressive silent hypoxemia, intubation's ineffectiveness in most patients, rapid progression to severe gasping, and finally, death. The lung biopsies of 19 post-mortem patients, as well as the pathophysiological analysis effectuated, suggest an active process of lung cell destruction (pneumolysis) by active viral replication in 
COVID-19, associated to persistent infiltration of inflammatory cells, as well as a continuous repair process, but with an intense reactive fibrotic activity and superimposed opportunistic infections that finally leads to death. Only $54 \%$ of the patients presented intra-alveolar hemorrhage and only $37 \%$ microthrombi. A photo of Kawasaki's disease-type COVID-19 tongue is shown.

Pneumolysis also helps explain the post-disease fibrosis, residual respiratory insufficiency, and exercise limitation (as sequels). This concept can signify substantial progress in pulmonology for this type of viral aggression to the lungs, useful during this pandemic, and possibly during future ones.

\section{Authors contribution}

G.Z-C.: Writing original draft, conceptualization, formal analysis, methodology, visualization. N.Z-D.: Writing, review and editing, formal analysis, methodology. F.J.M.: Biopsies, pathological photomicrographs, and writing pathological findings. M.G.R-S: Pathology preparation, photomicrographs and writing pathological findings. M.E.: Review and validation.

\section{Acknowledgments}

We acknowledge the late Prof. Dr. Gustavo Zubieta-Castillo (Sr.), our mentor. We also thank Lucrecia DeUrioste and Rafaela Zubieta-DeUrioste for their collaboration and suggestions. 


\section{References}

Ackermann, M., Verleden, S.E., Kuehnel, M., Haverich, A., Welte, T., Laenger, F., Vanstapel, A., Werlein, C., Stark, H., Tzankov, A., Li, W.W., Li, V.W., Mentzer, S.J., Jonigk, D., 2020. Pulmonary Vascular Endothelialitis, Thrombosis, and Angiogenesis in Covid-19. N. Engl. J. Med. 383, 120-128. https://doi.org/10.1056/nejmoa2015432

Adhikari, S.P., Meng, S., Wu, Y.J., Mao, Y.P., Ye, R.X., Wang, Q.Z., Sun, C., Sylvia, S., Rozelle, S., Raat, H., Zhou, H., 2020. Epidemiology, causes, clinical manifestation and diagnosis, prevention and control of coronavirus disease (COVID-19) during the early outbreak period: A scoping review. Infect. Dis. Poverty. https://doi.org/10.1186/s40249020-00646-X

Ai, T., Yang, Z., Hou, H., Zhan, C., Chen, C., Lv, W., Tao, Q., Sun, Z., Xia, L., 2020. Correlation of Chest CT and RT-PCR Testing for Coronavirus Disease 2019 (COVID-19) in China: A Report of 1014 Cases. Radiology. https://doi.org/10.1148/radiol.2020200642

Barisione, E., Grillo, F., Ball, L., Bianchi, R., Grosso, M., Pelosi, P., Patroniti, N., Lucia, A. De, Orengo, G., Gratarola, A., Verda, M., Cittadini, G., Mastracci, L., Fiocca, R., 2020.

Histopathologic Progression and Radiologic Correlation of COVID-19 Lung Parenchyma Using a Post-Mortem Mini-Invasive Transbronchial Lung Cryobiopsy Approach. SSRN.

Bartolf, A., Cosgrove, C., 2016. Pneumonia. Med. (United Kingdom). https://doi.org/10.1016/j.mpmed.2016.03.004

Barton, L.M., Duval, E.J., Stroberg, E., Ghosh, S., Mukhopadhyay, S., 2020. COVID-19 Autopsies, Oklahoma, USA. Am. J. Clin. Pathol. https://doi.org/10.1093/ajcp/aqaa062

Blasi, F., Aliberti, S., Pappalettera, M., Tarsia, P., 2007. 100 years of respiratory medicine: Pneumonia. Respir. Med. https://doi.org/10.1016/j.rmed.2007.02.016

Braimbridge, M. V., 1993. The history of thoracoscopic surgery. Ann. Thorac. Surg. https://doi.org/10.1016/0003-4975(93)90929-C

Brenner, S.R., 2021. Erythropoietin-induced hemoglobin subunit beta may stimulate innate immune RNA virus pattern recognition, suppress reactive oxygen species, reduce ACE2 viral doorway opening, and neutrophil extracellular traps against COVID-19. J. Med. Virol. https://doi.org/10.1002/jmv.26284

Dalakas, M.C., 2020. Guillain-Barré syndrome: The first documented COVID-19-triggered autoimmune neurologic disease: More to come with myositis in the offing. Neurol. Neuroimmunol. neuroinflammation. https://doi.org/10.1212/NXI.0000000000000781

Daniel, T.M., 2006. The history of tuberculosis. Respir. Med. https://doi.org/10.1016/j.rmed.2006.08.006

Diamanti, A.P., Rosado, M.M., Pioli, C., Sesti, G., Laganà, B., 2020. Cytokine release syndrome in COVID-19 patients, a new scenario for an old concern: The fragile balance between infections and autoimmunity. Int. J. Mol. Sci. https://doi.org/10.3390/ijms21093330

Edler, C., Schröder, A.S., Aepfelbacher, M., Fitzek, A., Heinemann, A., Heinrich, F., Klein, A., Langenwalder, F., Lütgehetmann, M., Meißner, K., Püschel, K., Schädler, J., Steurer, S., Mushumba, H., Sperhake, J.P., 2020. Dying with SARS-CoV-2 infection-an autopsy study of the first consecutive 80 cases in Hamburg, Germany. Int. J. Legal Med. https://doi.org/10.1007/s00414-020-02317-w

Ehrenfeld, M., Tincani, A., Andreoli, L., Cattalini, M., Greenbaum, A., Kanduc, D., AlijotasReig, J., Zinserling, V., Semenova, N., Amital, H., Shoenfeld, Y., 2020. Covid-19 and autoimmunity. Autoimmun. Rev. https://doi.org/10.1016/j.autrev.2020.102597 
Ehrenreich, H., Weissenborn, K., Begemann, M., Busch, M., Vieta, E., Miskowiak, K.W., 2020. Erythropoietin as candidate for supportive treatment of severe COVID-19. Mol. Med. 26, 58. https://doi.org/10.1186/s10020-020-00186-y

Feigin, R., 2004. Textbook of Pediatric Infectious Diseases (5th ed.), 5th ed. Sauders, W.B., Philadelphia, USA.

Felson, B., Rosenberg, L.S., Hamburger, M., 1949. Roentgen findings in acute Friedländer's pneumonia. Radiology 53, 559-565. https://doi.org/10.1148/53.4.559

Fishbane, S., Hirsch, J.S., 2020. Erythropoiesis-Stimulating Agent Treatment in Patients With COVID-19. Am. J. Kidney Dis. https://doi.org/10.1053/j.ajkd.2020.05.002

Galeotti, C., Bayry, J., 2020. Autoimmune and inflammatory diseases following COVID-19. Nat. Rev. Rheumatol. https://doi.org/10.1038/s41584-020-0448-7

Gattinoni, L., Marini, J.J., Pesenti, A., Quintel, M., Mancebo, J., Brochard, L., 2016. The "baby lung” became an adult. Intensive Care Med. https://doi.org/10.1007/s00134-015-4200-8

Geng, S., Mei, Q., Zhu, C., Yang, T., Yang, Y., Fang, X., Pan, A., 2020. High flow nasal cannula is a good treatment option for COVID-19. Hear. Lung. https://doi.org/10.1016/j.hrtlng.2020.03.018

Hadadi, A., Mortezazadeh, M., Kolahdouzan, K., Alavian, G., 2020. Does recombinant human Erythropoietin administration in critically ill COVID-19 patients have miraculous therapeutic effects? J. Med. Virol. 92, 915-918. https://doi.org/10.1002/jmv.25839

Leventhal, J., Angeletti, A., Cravedi, P., 2020. EPO in Patients With COVID-19: More Than an Erythropoietic Hormone. Am. J. Kidney Dis. https://doi.org/10.1053/j.ajkd.2020.06.002

Lin, L., Lu, L., Cao, W., Li, T., 2020. Hypothesis for potential pathogenesis of SARS-CoV-2 infection-a review of immune changes in patients with viral pneumonia. Emerg. Microbes Infect. https://doi.org/10.1080/22221751.2020.1746199

Madabhavi, I., Sarkar, M., Kadakol, N., 2020. CoviD-19: A review. Monaldi Arch. Chest Dis. https://doi.org/10.4081/monaldi.2020.1298

Mason, R.J., 2020. Pathogenesis of COVID-19 from a cell biology perspective. Eur. Respir. J. 55, 2000607. https://doi.org/10.1183/13993003.00607-2020

Miskowiak, K.W., 2020. Erythropoietin as possible treatment of brain diseases. Ugeskr. Laeger.

Mitra, P., Misra, S., Sharma, P., 2020. COVID-19 Pandemic in India: What Lies Ahead. Indian J. Clin. Biochem. https://doi.org/10.1007/s12291-020-00886-6

NYTimes, 2020. Coronavirus in the U.S.: Latest Map and Case Count. NYTimes.

Ouldali, N., Pouletty, M., Mariani, P., Beyler, C., Blachier, A., Bonacorsi, S., Danis, K., Chomton, M., Maurice, L., Le Bourgeois, F., Caseris, M., Gaschignard, J., Poline, J., Cohen, R., Titomanlio, L., Faye, A., Melki, I., Meinzer, U., 2020. Emergence of Kawasaki disease related to SARS-CoV-2 infection in an epicentre of the French COVID-19 epidemic: a time-series analysis. Lancet Child Adolesc. Heal. https://doi.org/10.1016/S2352-4642(20)30175-9

Pahal, P., Sharma, S., 2020. Typical Bacterial Pneumonia. StatPearls.

Pai, M., Behr, M.A., Dowdy, D., Dheda, K., Divangahi, M., Boehme, C.C., Ginsberg, A., Swaminathan, S., Spigelman, M., Getahun, H., Menzies, D., Raviglione, M., 2016. Tuberculosis. Nat. Rev. Dis. Prim. https://doi.org/10.1038/nrdp.2016.76

Pan, F., Ye, T., Sun, P., Gui, S., Liang, B., Li, L., Zheng, D., Wang, J., Hesketh, R.L., Yang, L., Zheng, C., 2020. Time Course of Lung Changes On Chest CT During Recovery From 2019 Novel Coronavirus (COVID-19) Pneumonia. Radiology. https://doi.org/10.1148/radiol.2020200370 
Periselneris, J.N., Brown, J.S., José, R.J., 2020. Pneumonia. Med. (United Kingdom). https://doi.org/10.1016/j.mpmed.2020.03.002

Petitjeans, F., Pichot, C., Ghignone, M., Quintin, L., 2016. Early severe acute respiratory distress syndrome: What's going on? Part I: pathophysiology. Anaesthesiol. Intensive Ther.

Pomara, C., Li Volti, G., Cappello, F., 2020. COVID-19 Deaths: Are We Sure It Is Pneumonia? Please, Autopsy, Autopsy, Autopsy! J. Clin. Med. https://doi.org/10.3390/jcm9051259

Richardson, S., Hirsch, J.S., Narasimhan, M., Crawford, J.M., McGinn, T., Davidson, K.W., Barnaby, D.P., Becker, L.B., Chelico, J.D., Cohen, S.L., Cookingham, J., Coppa, K., Diefenbach, M.A., Dominello, A.J., Duer-Hefele, J., Falzon, L., Gitlin, J., Hajizadeh, N., Harvin, T.G., Hirschwerk, D.A., Kim, E.J., Kozel, Z.M., Marrast, L.M., Mogavero, J.N., Osorio, G.A., Qiu, M., Zanos, T.P., 2020. Presenting Characteristics, Comorbidities, and Outcomes among 5700 Patients Hospitalized with COVID-19 in the New York City Area. JAMA - J. Am. Med. Assoc. 323, 2052-2059. https://doi.org/10.1001/jama.2020.6775

Robba, C., Battaglini, D., Ball, L., Patroniti, N., Loconte, M., Brunetti, I., Vena, A., Giacobbe, D.R., Bassetti, M., Rocco, P.R.M., Pelosi, P., 2020. Distinct phenotypes require distinct respiratory management strategies in severe COVID-19. Respir. Physiol. Neurobiol. https://doi.org/10.1016/j.resp.2020.103455

Sahebnasagh, A., Mojtahedzadeh, M., Najmeddin, F., Najafi, A., Safdari, M., Rezai Ghaleno, H., Habtemariam, S., Berindan-Neagoe, I., Nabavi, S.M., 2020. A Perspective on Erythropoietin as a Potential Adjuvant Therapy for Acute Lung Injury/Acute Respiratory Distress Syndrome in Patients with COVID-19. Arch. Med. Res. https://doi.org/10.1016/j.arcmed.2020.08.002

Sauter, J.L., Baine, M.K., Butnor, K.J., Buonocore, D.J., Chang, J.C., Jungbluth, A.A., Szabolcs, M.J., Morjaria, S., Mount, S.L., Rekhtman, N., Selbs, E., Sheng, Z.M., Xiao, Y., Kleiner, D.E., Pittaluga, S., Taubenberger, J.K., Rapkiewicz, A. V., Travis, W.D., 2020. Insights into pathogenesis of fatal COVID-19 pneumonia from histopathology with immunohistochemical and viral RNA studies. Histopathology. https://doi.org/10.1111/his.14201

Schilders, K.A.A., Eenjes, E., Riet, S. van, Poot, A.A., Stamatialis, D., Truckenmüller, R., Hiemstra, P.S., Rottier, R.J., 2016. Regeneration of the lung: Lung stem cells and the development of lung mimicking devices. Respir. Res. https://doi.org/10.1186/S12931-0160358-Z

Serafino Wani, R.L., 2013. Tuberculosis 2: Pathophysiology and microbiology of pulmonary tuberculosis. South Sudan Med. J.

Sohrabi, C., Alsafi, Z., O’Neill, N., Khan, M., Kerwan, A., Al-Jabir, A., Iosifidis, C., Agha, R., 2020. World Health Organization declares global emergency: A review of the 2019 novel coronavirus (COVID-19). Int. J. Surg. https://doi.org/10.1016/j.ijsu.2020.02.034

Soliz, J., Joseph, V., Soulage, C., Becskei, C., Vogel, J., Pequignot, J.M., Ogunshola, O., Gassmann, M., 2005. Erythropoietin regulates hypoxic ventilation in mice by interacting with brainstem and carotid bodies. J. Physiol. https://doi.org/10.1113/jphysiol.2005.093328

Soliz, J., Schneider-Gasser, E.M., Arias-Reyes, C., Aliaga-Raduan, F., Poma-Machicao, L., Zubieta-Calleja, G., Furuya, W.I., Trevizan-Baú, P., Dhingra, R.R., Dutschmann, M., 2020. Coping with hypoxemia: Could erythropoietin (EPO) be an adjuvant treatment of COVID19? Respir. Physiol. Neurobiol. 279, 103476. https://doi.org/10.1016/j.resp.2020.103476 Stevenson, 2010. Oxford Distionary of English.

Sureda, A., Alizadeh, J., Nabavi, S.F., Berindan-Neagoe, I., Cismaru, C.A., Jeandet, P., Łos, 
M.J., Clementi, E., Nabavi, S.M., Ghavami, S., 2020. Endoplasmic reticulum as a potential therapeutic target for covid-19 infection management? Eur. J. Pharmacol. https://doi.org/10.1016/j.ejphar.2020.173288

Tang, X., Du, R.H., Wang, R., Cao, T.Z., Guan, L.L., Yang, C.Q., Zhu, Q., Hu, M., Li, X.Y., Li, Y., Liang, L.R., Tong, Z.H., Sun, B., Peng, P., Shi, H.Z., 2020. Comparison of Hospitalized Patients With ARDS Caused by COVID-19 and H1N1. Chest.

https://doi.org/10.1016/j.chest.2020.03.032

Teuwen, L.-A., Geldhof, V., Pasut, A., Carmeliet, P., 2020. COVID-19: the vasculature unleashed. Nat. Rev. Immunol. 20, 389-391. https://doi.org/10.1038/s41577-020-0343-0

Tobin, M.J., Laghi, F., Jubran, A., 2020. Why COVID-19 Silent Hypoxemia is Baffling to Physicians. Am. J. Respir. Crit. Care Med. 202, 356-360. https://doi.org/10.1164/rccm.202006-2157cp

Toubiana, J., Poirault, C., Corsia, A., Bajolle, F., Fourgeaud, J., Angoulvant, F., Debray, A., Basmaci, R., Salvador, E., Biscardi, S., Frange, P., Chalumeau, M., Casanova, J.L., Cohen, J.F., Allali, S., 2020. Kawasaki-like multisystem inflammatory syndrome in children during the covid-19 pandemic in Paris, France: prospective observational study. BMJ. https://doi.org/10.1136/bmj.m2094

Wichmann, D., Sperhake, J.P., Lütgehetmann, M., Steurer, S., Edler, C., Heinemann, A., Heinrich, F., Mushumba, H., Kniep, I., Schröder, A.S., Burdelski, C., de Heer, G., Nierhaus, A., Frings, D., Pfefferle, S., Becker, H., Bredereke-Wiedling, H., de Weerth, A., Paschen, H.R., Sheikhzadeh-Eggers, S., Stang, A., Schmiedel, S., Bokemeyer, C., Addo, M.M., Aepfelbacher, M., Püschel, K., Kluge, S., 2020. Autopsy Findings and Venous Thromboembolism in Patients With COVID-19: A Prospective Cohort Study. Ann. Intern. Med. https://doi.org/10.7326/M20-2003

Woodruff, M.C., Ramonell, R.P., Nguyen, D.C., Cashman, K.S., Saini, A.S., Haddad, N.S., Ley, A.M., Kyu, S., Howell, J.C., Ozturk, T., Lee, S., Suryadevara, N., Case, J.B., Bugrovsky, R., Chen, W., Estrada, J., Morrison-Porter, A., Derrico, A., Anam, F.A., Sharma, M., Wu, H.M., Le, S.N., Jenks, S.A., Tipton, C.M., Staitieh, B., Daiss, J.L., Ghosn, E., Diamond, M.S., Carnahan, R.H., Crowe, J.E., Hu, W.T., Lee, F.E.H., Sanz, I., 2020. Extrafollicular B cell responses correlate with neutralizing antibodies and morbidity in COVID-19. Nat. Immunol. https://doi.org/10.1038/s41590-020-00814-Z

Wunderink, R.G., Woldenberg, L.S., Zeiss, J., Day, C.M., Ciemins, J., Lacher, D.A., 1992. The radiologic diagnosis of autopsy-proven ventilator-associated pneumonia. Chest. https://doi.org/10.1378/chest.101.2.458

Xie, X., Zhong, Z., Zhao, W., Zheng, C., Wang, F., Liu, J., 2020. Chest CT for Typical Coronavirus Disease 2019 (COVID-19) Pneumonia: Relationship to Negative RT-PCR Testing. Radiology. https://doi.org/10.1148/radiol.2020200343

Yan, R., Zhang, Y., Li, Y., Xia, L., Guo, Y., Zhou, Q., 2020. Structural basis for the recognition of SARS-CoV-2 by full-length human ACE2. Science (80-. ). https://doi.org/10.1126/science.abb2762

Zubieta-Calleja, G.R., Ardaya, G., Zubieta, N., Paulev, P.E.\& Z.-C.G., 2013. Tolerance to Hypoxia [WWW Document]. J Fisiol. URL https://zuniv.net/pub/TolerancetoHypoxiaFiziol.pdf

Zubieta-Calleja, G \& Zubieta-DeUrioste, N., 2020. El COVID-19 y las complicaciones Pulmonares: Neumólosis y Baja tolerancia a la Hipoxia. Com. Nac. Bioética 3, 27-30.

Zubieta-Calleja, G., 2020. Pneumolysis in COVID-19 Lung Disease,1st mention June 9th, 2020. 
Zubieta-Calleja, G., Zubieta-DeUrioste, N., 2020. Pneumolysis and "Silent Hypoxemia" in COVID-19. Indian J. Clin. Biochem. https://doi.org/10.1007/s12291-020-00935-0

Zubieta-Calleja, G.R., Paulev, P.E., Zubieta-Calleja, L., Zubieta-Castillo, G., 2007. Altitude adaptation through hematocrit changes. J. Physiol. Pharmacol.

Zubieta-Calleja, G.R., Zubieta-Castillo, G., 1989. High Altitude Pathology at 12,000 ft. Papiro, La Paz, Bolivia.

Zubieta-Calleja, G.R., Zubieta-DeUrioste, N., Venkatesh, T., Das, K., Soliz, J., 2020. COVID-19 and Pneumolysis Simulating Extreme High-altitude Exposure with Altered Oxygen Transport Physiology; Multiple Diseases, and Scarce Need of Ventilators: Andean Condor's-eye-view. Rev. Recent Clin. Trials. https://doi.org/10.2174/1574887115666200925141108

Zubieta-Castillo, G.R., Zubieta-Calleja, G.R., Zubieta-Calleja, L., 2006. Chronic mountain sickness: The reaction of physical disorders to chronic hypoxia. J. Physiol. Pharmacol. 57, 431-42. 


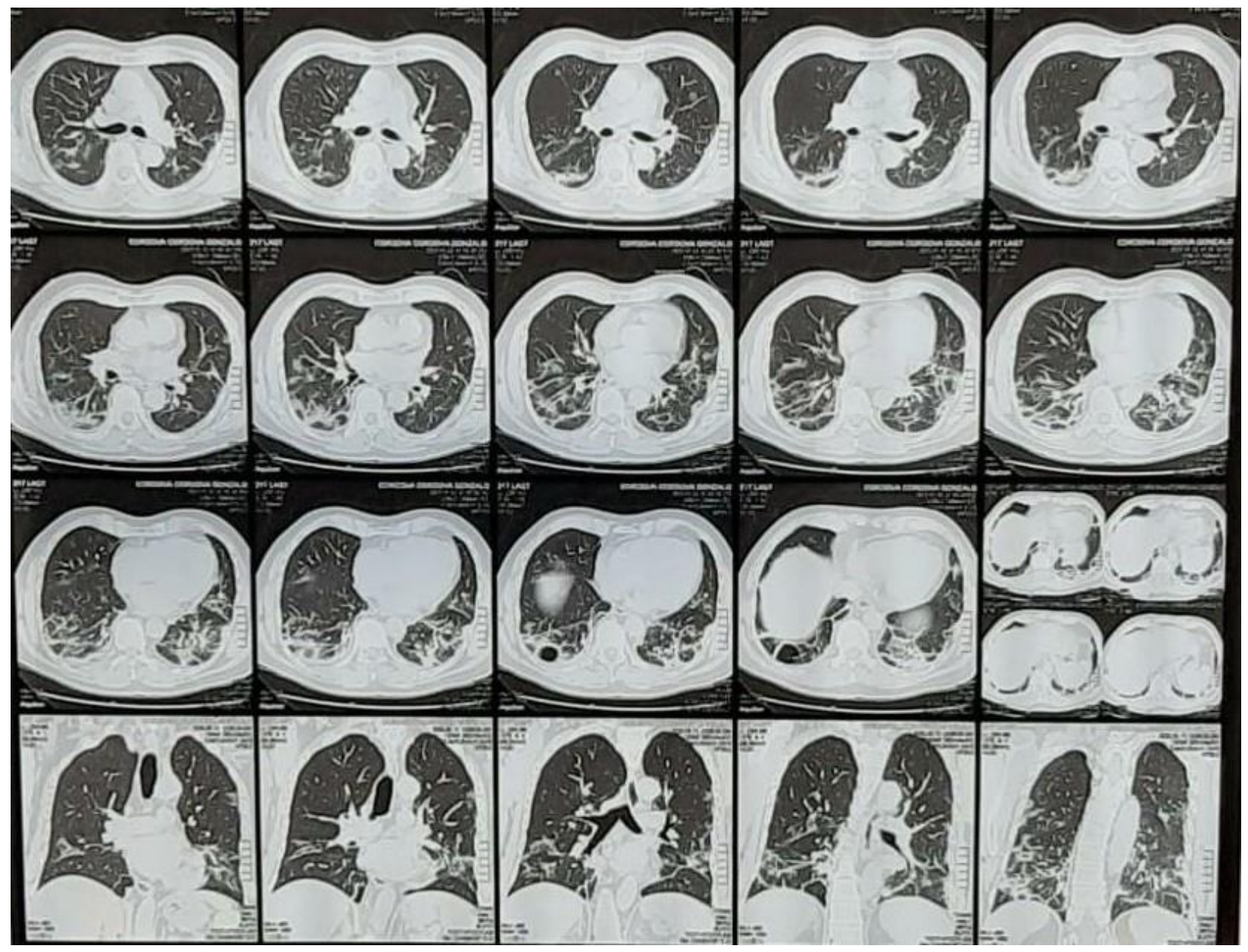

Fig. 1. CAT scan of a typical patient with COVID-19 lung disease. Courtesy of Centro de Estudios Tomográficos (CET) La Paz, Bolivia. Pneumolysis can be so severe that even bullae can be formed ( $3^{\text {rd }}$ row, middle frame). 

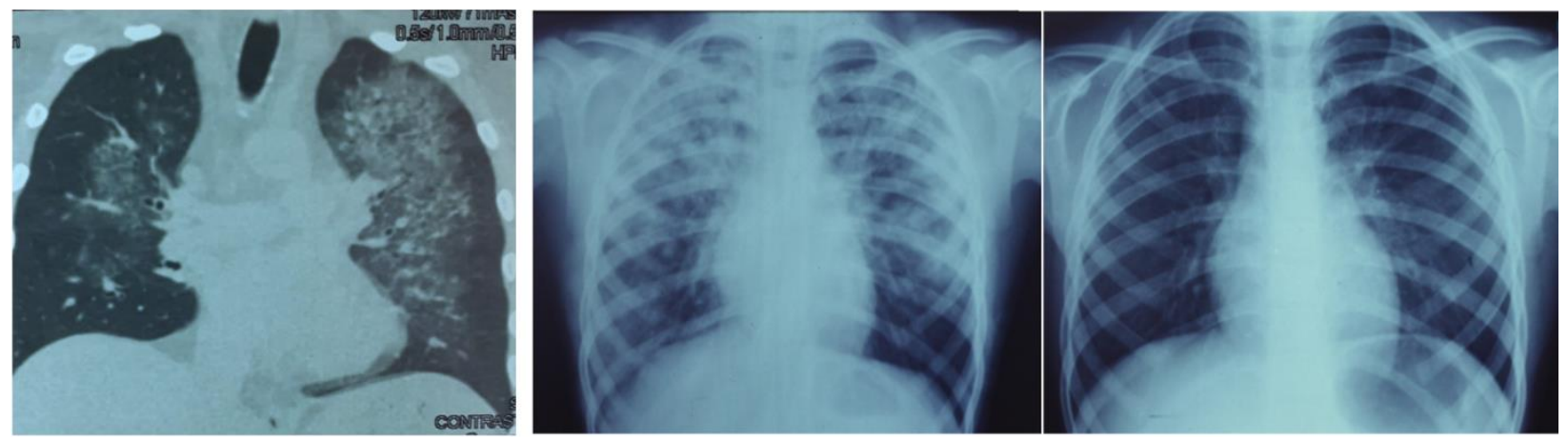

Fig. 2. High Altitude Pulmonary Edema. Left Chest CAT scan, where patchy irregular distribution of edema is shown in both lung areas. Middle X-Rays showing a full blown HAPE. Right 48 hours after showing full clearance of edema from both lungs. 

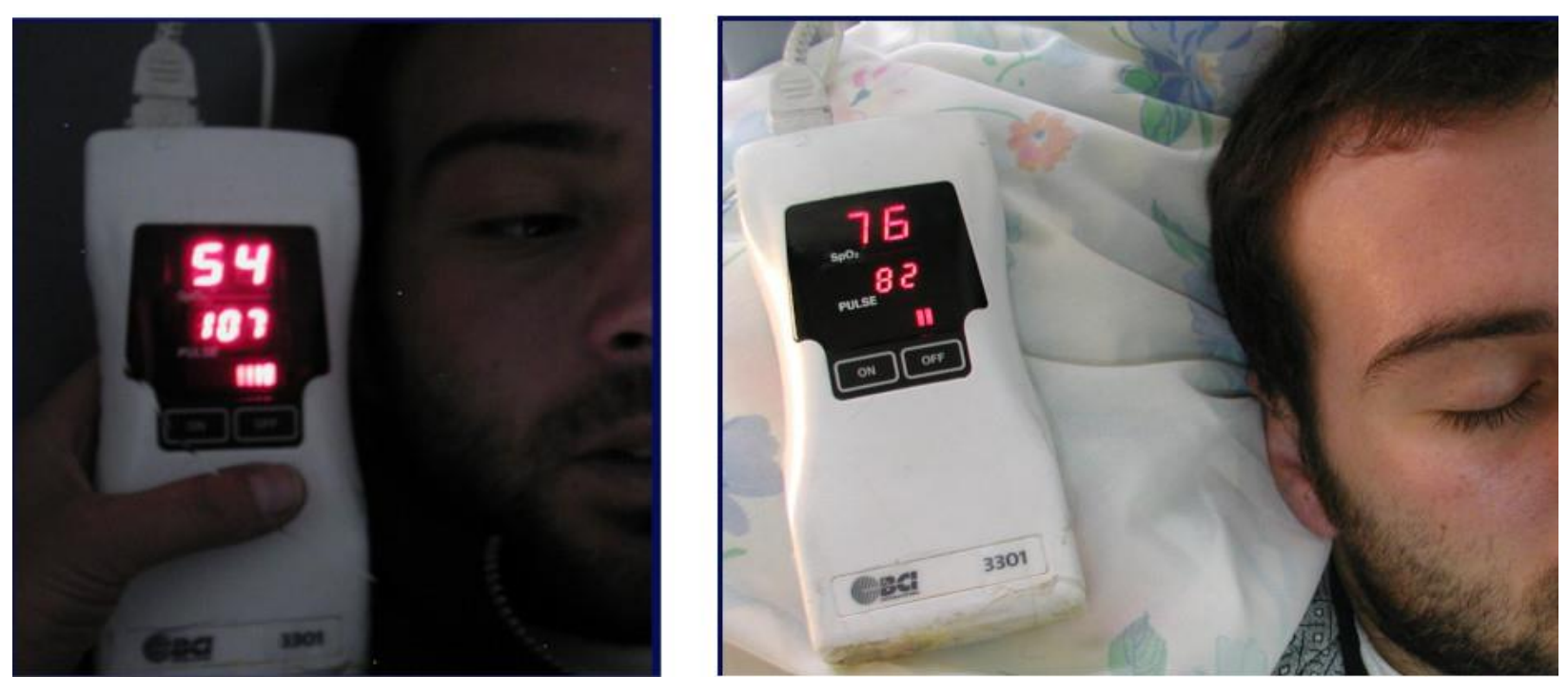

Fig. 3. This European patient who presented severe HAPE, after attempting to climb Mount Huayna Potosi $(6,088 \mathrm{~m}$, 19,973ft) shortly after arriving to La Paz, presented a severe HAPE. Left the moment of arrival to our Institute with an $\mathrm{SpO}_{2}$ of $54 \%$ and a $\mathrm{PaO}_{2}$ of $30 \mathrm{mmHg}$ (similar to that found on the summit of Mt. Everest). His breathing was not dyspneic, similar to a "Silent Hypoxemia". Right, Next day after initial treatment. He fully recovered in a couple of days and went back home to play intensive sports as though nothing had happened. 


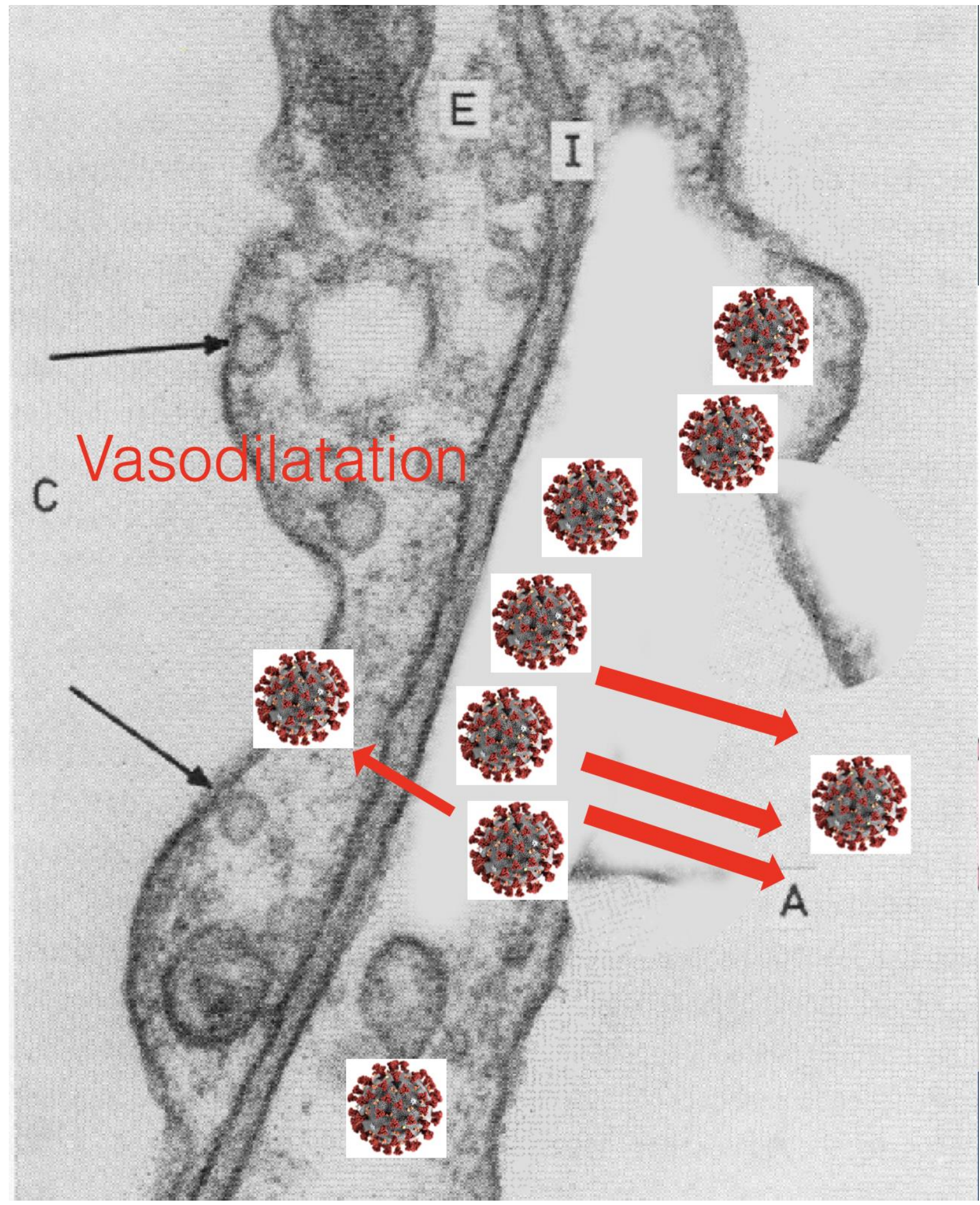

Fig. 4. Diagram depicting possible scenario of $\mathrm{CoV}-2$ reproduction within type II pneumocytes, inducing the rupture of the cellular wall and exodus of Coronavirus with replicated RNA, that migrate to infect other pneumocytes. The rupture of the pneumocyte wall would likewise induce alveolar capillaries vasodilatation of alveolar capillaries and possible entrance into the circulation and adhesion to endothelial ACE-2 receptors, resulting in coagulopathies. 

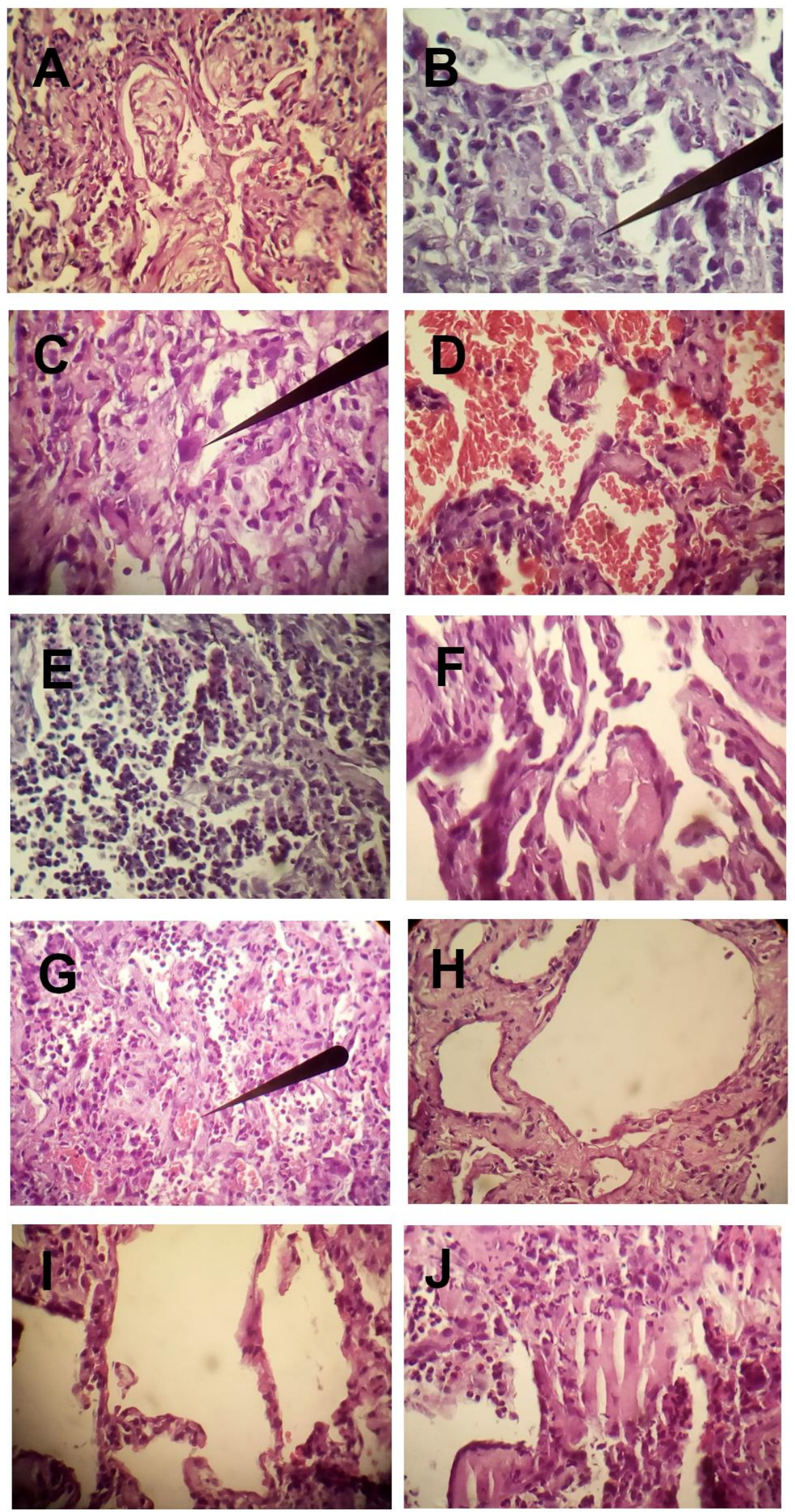
Fig. 5. A) Masson bodies. Note the hyaline border fixed to the alveolar walls. B) Intra-alveolar macrophages. C) Alveolar coating cells with nuclear atypia, reactive pneumocytes and reparative fibrosis. D) Intra-alveolar hemorrhage. Presence of intra-alveolar and septal interstitial polymorphonuclear cells. Note the intra-alveolar septum thickening with moderate inflammatory infiltrates. E) Intra-alveolar abscesses. F) Fibrinoid deposits. G) Microthrombus. H) Intense septal fibrosis. Note in the lower part of the larger alveoli, the presence of a remanent of a hyaline membrane. I) Area of alveolar rupture (emphysema). Photo and pathological analyses were performed by Dr. Felipe de Jesus Montelongo (Head Intensive Care) and Dr. Manuel Gabriel Romo Sanchez (Pulmonary Pathology specialist) from the Hospital General de Ecatepec Las Americas, ISEM, México. 


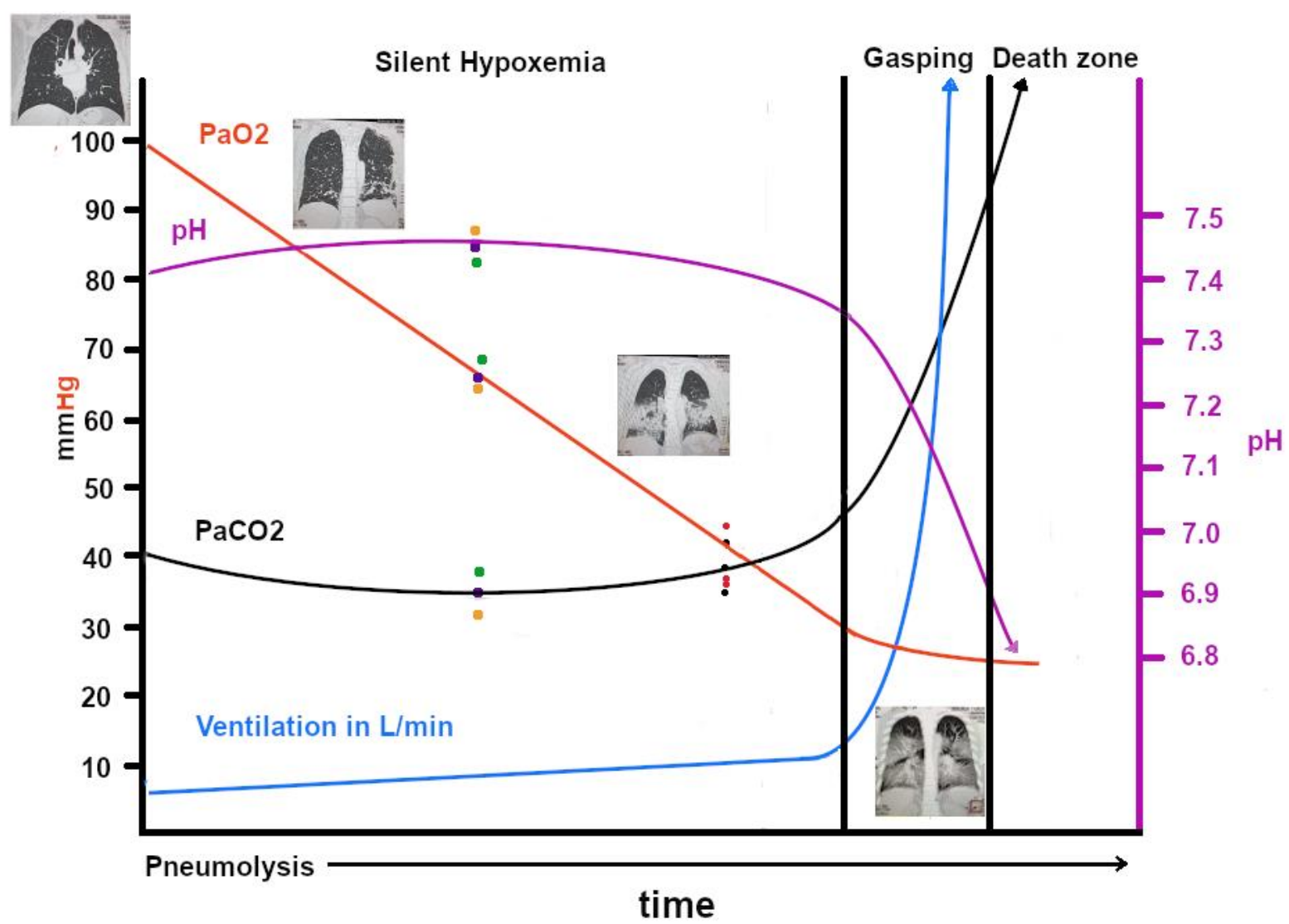

Fig. 6. This graph developed by both Zubieta authors, shows the probable blood gases, acid-base, ventilation and hypoxemia evolution in COVID-19 disease at sea level. Note that the pH scale is at the right and the $\mathrm{PaO}_{2}, \mathrm{PaCO}_{2}$ and ventilation scale is at the left. The CAT scan images show how as the disease spreads throughout the lungs, the gas exchange compromise increases thereby reducing the oxygen transport through the alveolar-capillary membrane. The green, black and yellow dots represent actual blood gases obtained from https://www.youtube.com/watch?v=_KMLW8eO0q0 by Dr. Shiv Kumar Singh. The black and red dots are from (Tobin et al., 2020). 


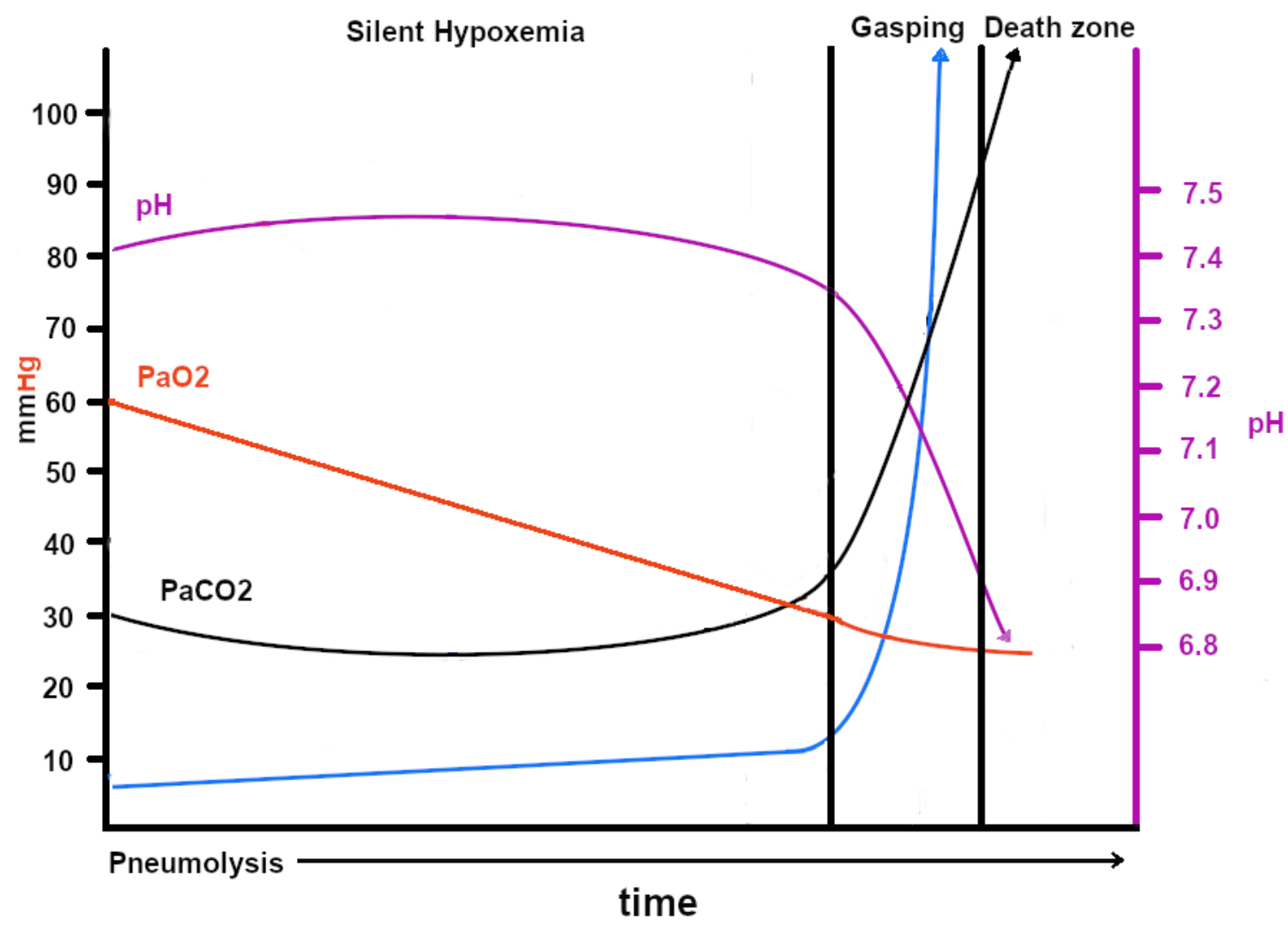

Fig. 7. This graph developed by both Zubieta authors, shows the probable blood gases acid-base ventilation and hypoxemia evolution in COVID-19 disease at 3,500m $(12,000 \mathrm{ft})$ of altitude where the normal $\mathrm{PaO}_{2}$ is $60 \mathrm{mmHg}$ and the normal $\mathrm{SpO}_{2}$ is $88-92 \%$. Notice that the gradual $\mathrm{PaO}_{2}$ decrease slope is much lower and hence related to a higher tolerance to hypoxia than at sea level (with a lower $\mathrm{PaCO}_{2}=30 \mathrm{mmHg}$ ), becomes an advantage for survival until immunity ensues. The death rates due to COVID-19 are much lower at high altitude in comparison to sea level. 


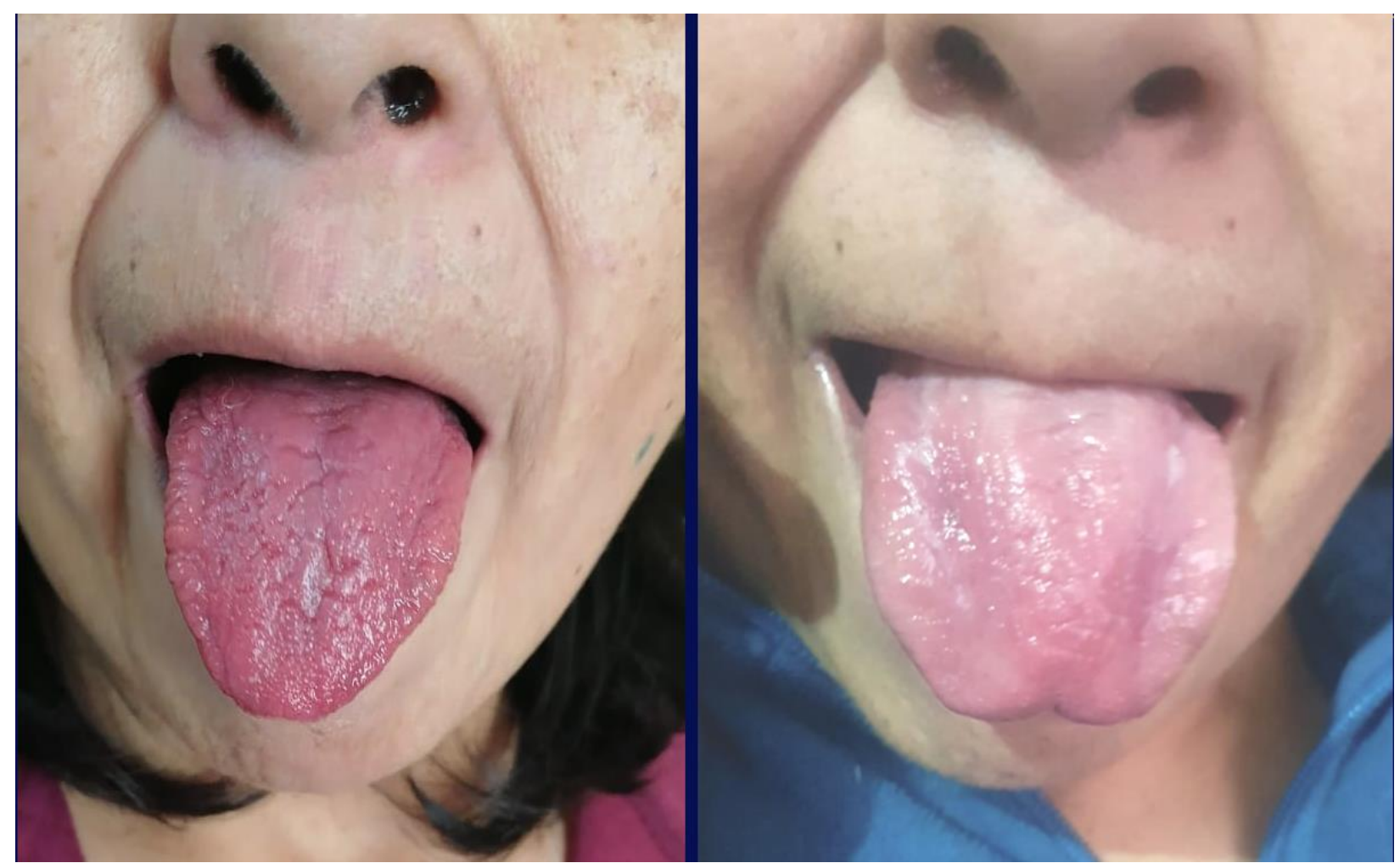

Fig. 8. Left, the tongue in a COVID-19 patient with a very peculiar color, similar to Kawasaki's Disease tongue classically described as a "strawberry tongue", associated to vasculitis. Right, Two weeks later evolution after treatment and gradual recovery from the pneumolysis. 